Proc. Estonian Acad. Sci. Eng., 2002, 8, 2, 101-113

\title{
Analysis of saddle-shaped cable networks with different contour structures
}

\author{
Valdek Kulbach, Juhan Idnurm, and Ivar Talvik \\ Department of Structural Design, Tallinn Technical University, Ehitajate tee 5, 19086 Tallinn, \\ Estonia; vkulbach@edu.ttu.ee \\ Received 2 April 2002, in revised form 11 April 2002
}

\begin{abstract}
Usually the cable network of a saddle-shaped roof is formed inside a contour of two inclined plane arches which are supported by massive counterforts at lower ends. In the present paper advantages of hypar-networks encircled by a spatial contour beam with elliptical layout and without any external horizontal supports have been presented. Both discrete and continuous calculation methods can be used for the analysis of the stress-strain state of those networks. A system of non-dimensional parameters is used to study the effect of variable geometrical and stiffness properties on the behaviour of an elliptical roof structure. Comparison of the behaviour of cable networks with different contour beams is given.
\end{abstract}

Key words: cable structure, continuous analysis, discrete analysis, geometrical non-linearity, hanging roof, suspended roof, prestressed cable network, suspension structure.

\section{INTRODUCTION}

Making use of prestressed cable networks in roof structures permit the designer to span large areas in an efficient way. The net surface is formed by prestressing a two-way cable system within a spatial contour structure. In the studies of the last decades, reported in $\left[{ }^{1,2}\right]$, two basic models for the analysis of cable networks, continuous and discrete, have been used.

Discrete schemes, starting with the paper $\left[^{3}\right]$, have utilized straight bar elements to model the cable links between the nodes and permit an analysis of the networks without remarkable geometrical restrictions. Continuous schemes may be applied only to networks with configurations that are convenient to describe analytically, like hyperbolic paraboloid, for example.

Due to the complex nature of interaction between the contour and the network, the behaviour of cable roofs is strongly dependent on geometrical and 
stiffness characteristics of its elements. The contour structure makes up a substantial part of the overall cost of the structure. In practice more often heavy and rigid supports have been used. Buchholdt $\left[{ }^{2}\right]$ refers to the tendency to overdimension the support beams. Optimizing of the supports results in more flexible boundary structures which can modify the overall behaviour of the system and therefore deserve particular attention. Godbole et al. $\left[{ }^{4}\right]$, Majowiecki and Zoulas $\left[{ }^{5}\right]$, and Mitsugi $\left[{ }^{6}\right]$ have introduced support displacements in the discrete numerical model of cable structures.

The present paper treats cable networks with two different contour structures. The first one is formed inside a contour of two inclined planar arches. Regions of the network surface of this kind have essential curvatures near the counterforts, while the surface near the arch crowns is quite flat and therefore susceptible to vibrations under the action of fluctuating wind. The other network is a hypar with elliptical layout. Its contour is formed as a spatially curved beam without any external horizontal supports (Fig. 1). Both discrete and continuous
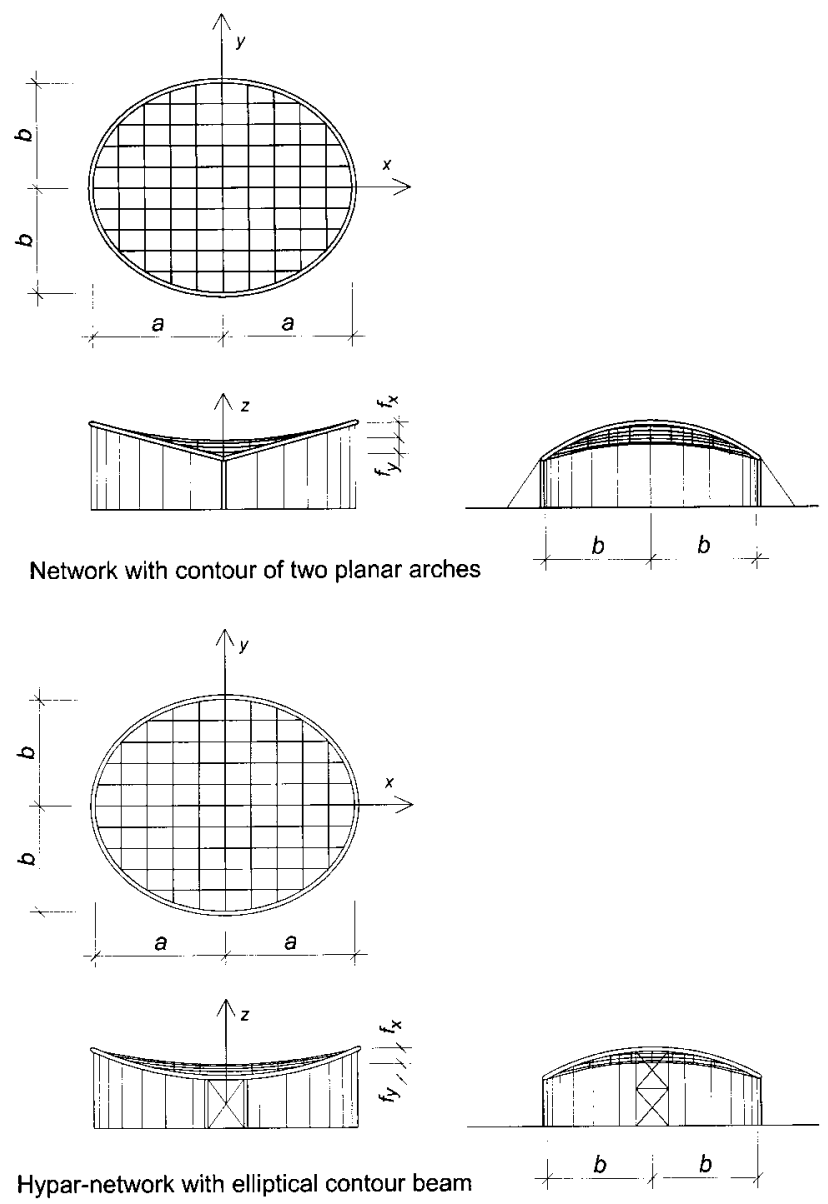

Fig. 1. Models of saddle-shaped networks with different contour structures. 
methods have been applied for their analysis. As all orthogonal networks, hypar networks can be prestressed only if the crossing cables have been fixed at the nodes. In case of continuous analysis, the contact load between two families of cables is regarded as continuous.

The results of the study demonstrate the effect of the variable geometrical and stiffness parameters on the performance of suspended cable roofs, emphasizing certain advantages of the contour flexibility on the static response of the structure. The proposed continuous model enables us to describe the complex non-linear structure including the interaction of the flexible contour with the cable network.

\section{DISCRETE ANALYSIS}

The complex structural configuration consists of two substructures - the network and the contour beam. The common assumptions about the linear strain diagram of materials and negligible weight of the network with regard to other loads were made. The cables were regarded as geometrically non-linear bars without flexural rigidity, and contour beams as linear beam elements. The network consists of two families of cables - the carrying and the stretching ones. At every node we have a point contact between the carrying and the stretching cable. After loading the network, the contact load changes; corresponding condition of equilibrium of the node $i, k$ can be expressed from the vector diagram in Fig. 2, where $r_{i, k}$ is the radius vector and $u_{i, k}$ is the displacement vector of the node $i, k ; S_{i, k}$ and $T_{i, k}$ are the internal forces of the $k$ th section of the $i$ th carrying cable and the $i$ th section of the $k$ th stretching cable. The equations of deformation compatibility for the $k$ th section of the $i$ th carrying cable and the $i$ th section of the $k$ th stretching cable may be written in the form

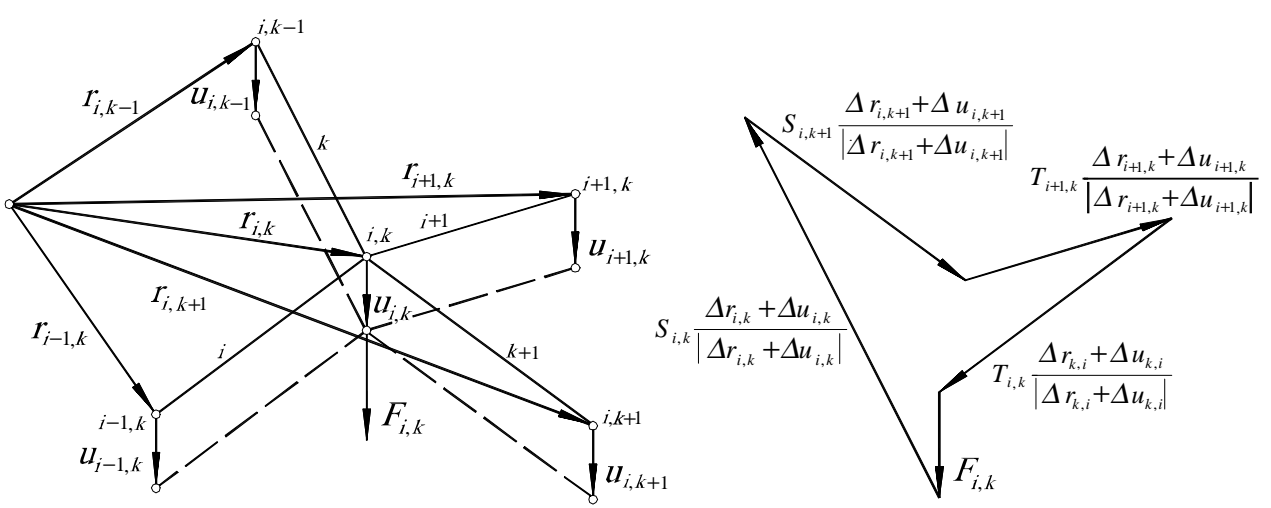

Fig. 2. Schematic of the equilibrium of the node $i, k$ of a cable network. 


$$
\begin{gathered}
\frac{\Delta u_{i, k}\left|\Delta r_{i, k}+0.5 \Delta u_{i, k}\right|}{\Delta r_{i, k}^{2}}=\frac{S_{i, k}-S_{0, i, k}}{E_{i} A_{i}}, \\
\frac{\Delta u_{k, i}\left|\Delta r_{k, i}+0.5 \Delta u_{k, i}\right|}{\Delta r_{k, i}{ }^{2}}=\frac{T_{i, k}-T_{0, i, k}}{E_{k} A_{k}},
\end{gathered}
$$

where $E_{i} A_{i}$ and $E_{k} A_{k}$ are the tension stiffness of the $i$ th carrying and the $k$ th stretching cable, $\Delta r_{i, k}=r_{i, k}-r_{i, k-1}$ and $\Delta u_{i, k}=u_{i, k}-u_{i, k-1}$ are the changes of corresponding vectors for the $i$ th carrying cable, $\Delta r_{k, i}=r_{k, i}-r_{k, i-1}$ and $\Delta u_{k, i}=u_{k, i}-u_{k, i-1}$ are the changes of the vectors for the $k$ th stretching cable, and index 0 denotes the initial prestressed state before loading.

Displacements of the contour nodes of the network are to be expressed by linear combinations of the products of all cable forces and the corresponding displacements of nodes of the contour beam, caused by the unit force.

Considering the action of vertical loads, determination of the cable forces and displacements of the nodes of an orthogonal network can be essentially simplified $\left[{ }^{7}\right]$. In this case the horizontal component of internal forces for all sections of every cable is constant. At the same time, additional simplifications may be applied. Lateral displacements of the nodes and the corresponding force components may be ignored both in the conditions of equilibrium as well as in the equations of deformation compatibility. The longitudinal displacements of the network's internal nodes may be eliminated by means of summation over all the members of the equations of deformation compatibility. Horizontal displacements of the contour nodes may be expressed by corresponding deflections under the action of all the cable forces. Vertical displacements of the contour nodes are usually prevented by fixing the contour structure to the wall columns. In this case the conditions of equilibrium are to be applied to every node and the equations of deformation compatibility for every cable can be expressed as

$$
\begin{aligned}
& G_{i} \frac{\left(z_{i, k-1}-2 z_{i, k}+z_{i, k+1}\right)+\left(w_{i, k-1}-2 w_{i, k}+w_{i, k+1}\right)}{a} \\
& \quad+H_{i} \frac{\left(z_{i-1, k}-2 z_{i, k}+z_{i+1, k}\right)+\left(w_{i-1, k}-2 w_{i, k}+w_{i+1, k}\right)}{b}-F_{i, k}=0, \\
& \sum\left(w_{i, k+1}-w_{i, k}\right)\left[\left(z_{i, k+1}-z_{i, k}\right)+0.5\left(w_{i, k+1}-w_{i, k}\right)\right] \\
& \quad\left(G_{i}-G_{0 i}\right) a^{2} \frac{\sum \sqrt{\left[1+\left(z_{i, k+1}-z_{i, k}\right)^{2}\right]^{3}}}{E_{i} A_{i}}-\left(u_{i, m}-u_{i, 0}\right) a,
\end{aligned}
$$




$$
\begin{aligned}
& \sum\left(w_{i+1, k}-w_{i, k}\right)\left[\left(z_{i+1, k}-z_{i, k}\right)+0.5\left(w_{i+1, k}-w_{i, k}\right)\right]= \\
& =\left(H_{i}-H_{0 i}\right) b^{2} \frac{\sum \sqrt{\left[1+\left(z_{i+1, k}-z_{i, k}\right)^{2}\right]^{3}}}{E_{k} A_{k}}-\left(v_{k, n}-v_{k, 0}\right) b,
\end{aligned}
$$

where $G_{0 i}$ and $G_{i}$ are the horizontal force of the $i$ th carrying cable before and after loading the network, $H_{0 k}$ and $H_{k}$ are the same for the $k$ th stretching cable, and $u_{i, m}, u_{i, 0}, v_{k, n}$, and $v_{k, 0}$ are the displacements of the contour nodes of the $i$ th carrying and $k$ th stretching cable under the action of all the cable forces. They may be determined by multiplying the cable forces and the corresponding ordinates of influence lines, constructed for displacements of nodes of the contour beam. Summation in (4) is to be extended over all the sections of the $i$ th carrying cable and summation in (5) over all the sections of the $k$ th stretching cable.

\section{CONTINUOUS MODEL FOR ANALYSIS OF HYPAR-NETWORKS}

An orthogonal hypar-network in Fig. 1 consists of concave carrying and convex stretching cables and may be described as a translatory surface

$$
z=\frac{f_{x} x^{2}}{a^{2}}-\frac{f_{y} y^{2}}{b^{2}} .
$$

In case of vertical loading, the condition of equilibrium and the equations of deformation compatibility may be written in the form $\left[{ }^{8}\right]$

$$
\begin{gathered}
\frac{G \delta^{2}(z+w)}{\delta x^{2}}+\frac{H \delta^{2}(z+w)}{\delta y^{2}}-p=0 \\
\int_{-x_{1}}^{x_{1}} \frac{\delta w}{\delta x}\left(\frac{\delta z}{\delta x}+0.5 \frac{\delta w}{\delta x}\right) \mathrm{d} x=\frac{\left(G-G_{0}\right) \int_{-x_{1}}^{x_{1}}\left[1+\left(\frac{\delta z}{\delta x}\right)^{2}\right]^{3 / 2} \mathrm{~d} x}{E t_{x}}-2 u_{1}(y), \\
\int_{-y_{1}}^{y_{1}} \frac{\delta w}{\delta y}\left(\frac{\delta z}{\delta y}+0.5 \frac{\delta w}{\delta y}\right) \mathrm{d} x=\frac{\left(H-H_{0}\right) \int_{-y_{1}}^{y_{1}}\left[1+\left(\frac{\delta z}{\delta y}\right)^{2}\right]^{3 / 2} \mathrm{~d} x}{E t_{y}}-2 v_{1}(x),
\end{gathered}
$$

where $u, v$, and $w$ are the displacements in the direction of axes $x, y$, and $z$, respectively; $E t_{x}$ and $E t_{y}$ are the stiffnesses of the carrying and stretching cables per unit width, $u_{1}(y)$ and $v_{1}(x)$ are the horizontal displacements of the 
contour beam caused by cable forces $\Delta G=\left(G-G_{0}\right)$ and $\Delta H=\left(H-H_{0}\right)$, $x_{1}=a\left(1-y^{2} / b^{2}\right)^{1 / 2}$, and $y_{1}=b\left(1-x^{2} / a^{2}\right)^{1 / 2}$ are coordinates of the contour beam for integration.

Full analogy exists between the algebraic equations (7)-(9) and the differential equations (3)-(5). Vertical displacements of the network and horizontal displacements of its contour beam may be approximated as follows:

$$
\begin{gathered}
w(x, y)=w_{00}\left(\frac{x^{2}}{a^{2}}+\frac{y^{2}}{b^{2}}-1\right), \\
\frac{u_{1}(y)=5\left(\Delta G b^{2}-\Delta H a^{2}\right) b \sqrt{a b}\left(1-\frac{y^{2}}{b^{2}}\right)^{1 / 2}}{72 E_{\mathrm{c}} I_{\mathrm{c}}}, \\
\frac{v_{1}(y)=5\left(\Delta H a^{2}-\Delta G b^{2}\right) a \sqrt{a b}\left(1-\frac{x^{2}}{a^{2}}\right)^{1 / 2}}{72 E_{\mathrm{c}} I_{\mathrm{c}}},
\end{gathered}
$$

where $E_{\mathrm{c}} I_{\mathrm{c}}$ is the flexural stiffness of the contour beam.

Substituting Eqs. (10), (11), and (12) into Eqs. (7), (8), and (9) and using well-known Galjorkin procedures, we obtain the following system of equations for the relative deflection of the network and the cable forces, presented by nondimensional parameters in the following generalized form $\left[{ }^{9}\right]$

$$
\begin{aligned}
(1+\psi+4 \xi) \zeta_{0}^{3} & +3[(1-\alpha \psi)+2(1-\alpha) \zeta] \zeta_{0}^{2} \\
& +\left\{2\left[\left(1+\alpha^{2} \psi\right)+(1-\alpha)^{2} \xi\right]+p_{0}^{*}\left(1+\alpha^{-1}\right)\right\} \zeta_{0}=p^{*}, \\
G= & G_{0}+\Phi \zeta_{0}\left[\left(2+\zeta_{0}\right)+2\left(1-\alpha+\zeta_{0}\right) \xi\right], \\
H= & H_{0}-\beta^{2} \Phi \zeta_{0}\left[\left(2 \alpha-\zeta_{0}\right) \psi-2\left(1-\alpha+\zeta_{0}\right) \xi\right],
\end{aligned}
$$

where $\zeta_{0}=w_{00} / f_{x}$ is the relative deflection of the network, $\alpha=f_{y} / f_{x}, w_{00}$ is the deflection at the centre of the network,

$$
\begin{gathered}
\psi=a^{4} t_{y}\left(1+\kappa_{y}\right) /\left[b^{4} t_{x}\left(1+\kappa_{x}\right)\right], \quad \kappa_{x}=5 f_{x}^{2} /\left(3 a^{2}\right), \quad \kappa_{y}=5 f_{y}^{2} /\left(3 b^{2}\right), \\
\xi=5 E t_{y} a^{3}(a / b)^{1 / 2} /\left[72 E_{\mathrm{c}} I_{\mathrm{c}}\left(1+\kappa_{x}\right)\right] \\
p^{*}=p a^{2} /\left(2 f_{x} \Phi\right), \quad p_{0}^{*}=p_{0} a^{2} /\left(2 f_{x} \Phi\right), \\
\Phi=15 E t_{x} f_{x}^{2} /\left[9 a^{2}\left(1+\kappa_{x}\right)(1+\mu \xi)\right], \quad \mu=1+\psi^{-1}
\end{gathered}
$$


Here $p$ is the uniform loading, $p_{0}$ is the prestressing contact load between the cables, $\psi, \kappa_{x}$, and $\kappa_{y}$ are geometrical parameters, $\xi$ is the parameter of contour stiffness, $p^{*}$ is the loading parameter, $p_{0}^{*}$ is the prestressing parameter, and $\Phi$ is the stiffness parameter of the cables.

Equations (13), (14), and (15) are very similar to equations, derived for double-cabled planar truss structures $\left[{ }^{10}\right]$. Significant difference in the behaviour of stretching cables under the action of loading should be pointed out.

\section{DEPENDENCE OF THE BEHAVIOUR OF A HYPAR-NETWORK ON ITS MAIN PARAMETERS}

The main variable parameters of a hypar-network with given dimensions $a, b, f=f_{x}+f_{y}$, and $t=t_{x}+t_{y}$, are the geometrical factors $\alpha=f_{y} / f_{x}$ and $\tau=t_{y} / t_{x}$ and the stiffness parameter of the contour beam $\xi ; t_{x}$ and $t_{y}$ are the equivalent thicknesses of the network in directions $x$ and $y$. Stiffness of the contour beam is a very important factor in the stress-strain state of the network as well as in total material consumption of the roof structure as a whole.

A hypar-network with dimensions $a=30 \mathrm{~m}, \quad b=24 \mathrm{~m}, f=7.2 \mathrm{~m}$, $t=1.2 \mathrm{~mm}$ was chosen for detailed analysis. A structure with the following parameters was considered as the basic case: $t_{x}=t_{y}=0.6 \mathrm{~mm}, \alpha=f_{y} / f_{x}=0.5$, tubular contour beam $\varnothing 2400 \times 32 \mathrm{~mm}(\xi=5)$.

The diagrams in Figs. 3 and 4 illustrate how the network deflection and the cable forces depend on the loading for different ratios of cross-section areas of the cables. It is worth to mention that smaller curvatures of the stretching cables are to be preferred as to the effect on network deflection and cable forces. That phenomenon may be explained by more efficient action of relatively flat stretching cables as tension rods for the contour beam. On the other hand, in this case higher values of the prestress are needed to keep the stretching cables in tension.

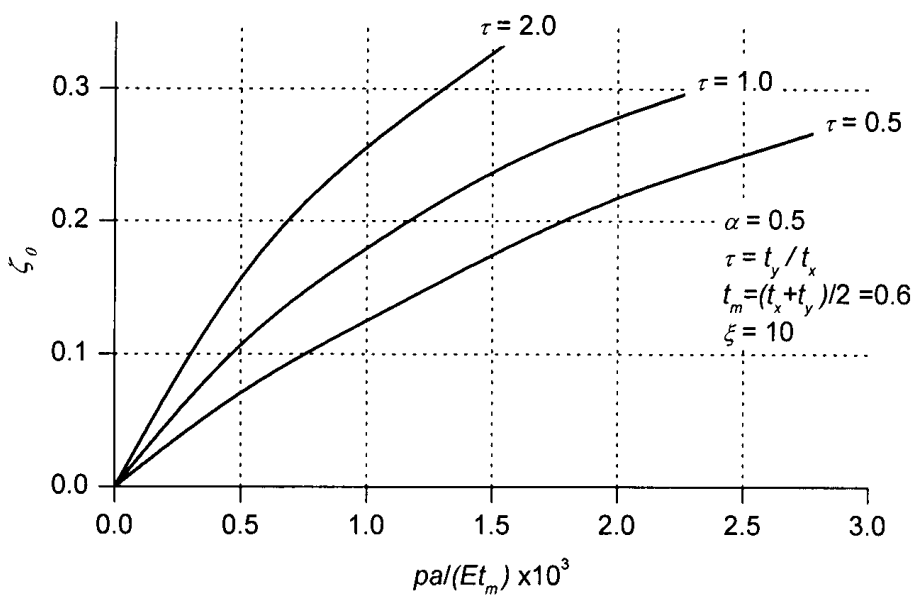

Fig. 3. Network deflection with uniform loading, effect of the geometrical parameter $\tau$. 


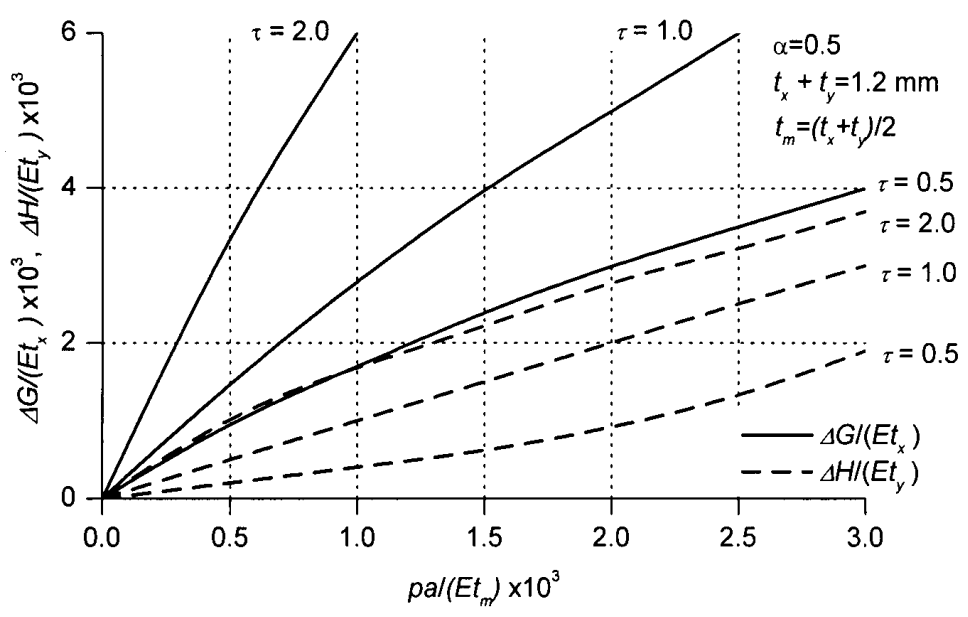

Fig. 4. Variation of cable forces with uniform loading for different values of $\tau$.

Figures 5 and 6 demonstrate the effect of variation of flexural stiffness of the contour beam on the network deflections and cable forces. The effect of geometrical non-linearity is most considerable in case of low stiffness values of the contour beam. Forces in stretching cables decrease with increasing contour stiffness. The relation between deflections, cable forces, and geometrical factor $\alpha$ is presented in Figs. 7 and 8.

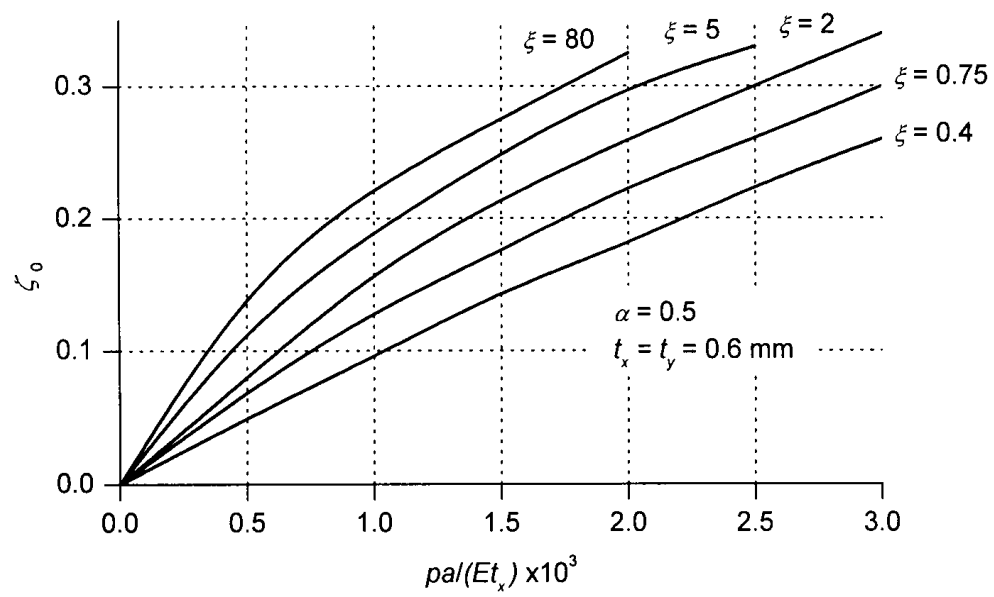

Fig. 5. Network deflections with uniform loading, effect of the stiffness $\xi$ of the contour beam. 


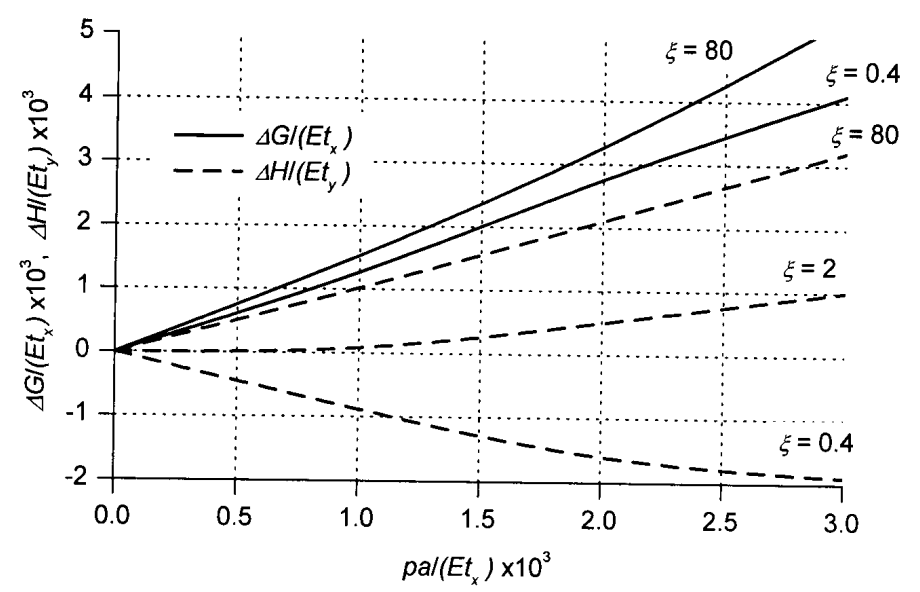

Fig. 6. Variation of cable forces with uniform loading, effect of the stiffness $\xi$ of the contour beam.

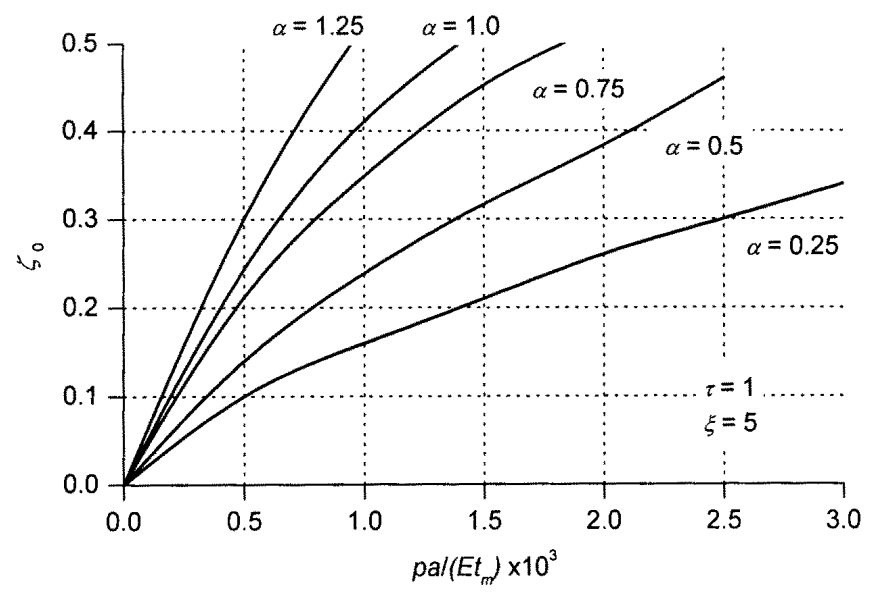

Fig. 7. Network deflection with uniform loading, effect of the geometrical parameter $\alpha$.

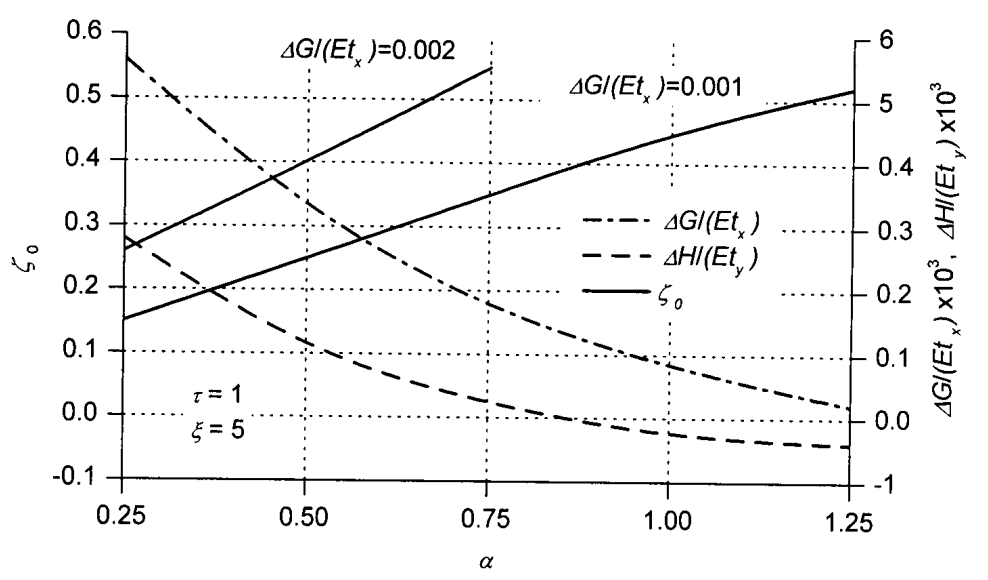

Fig. 8. Network deflection with uniform loading, effect of the geometrical parameter $\alpha$. 


\section{COMPARISON OF COUNTERFORT-SUPPORTED NETWORKS AND HYPAR-NETWORKS}

In order to find out the influence of the contour beam configuration on the behaviour of the structure, the hypar-networks, described in Section 4, were compared with networks which have counterfort-supported contour of two inclined parabolic arches. The enclosed area under both roofs is equal. Bending stiffness of the contour beam is corresponding to the basic model of the previous section. The results of the comparison show the general tendency that the hypar-network with elliptical layout is able to resist normal roof loads with very flexible contour beam $(\xi=80)$, while the corresponding network with inclined arches looses its bearing capacity under the action of relatively small loading due to the slackening of stretching cables. A selection of comparative results is presented in Figs. 9-13.

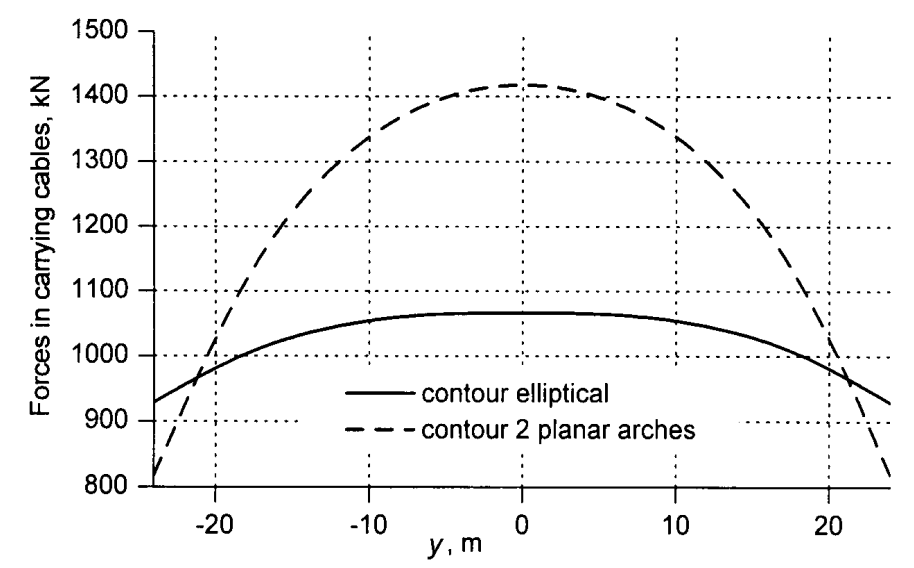

Fig. 9. Deflection of the central stretching cable on $y$ axis with uniform network loading $p=2 \mathrm{kN} / \mathrm{m}^{2}$.

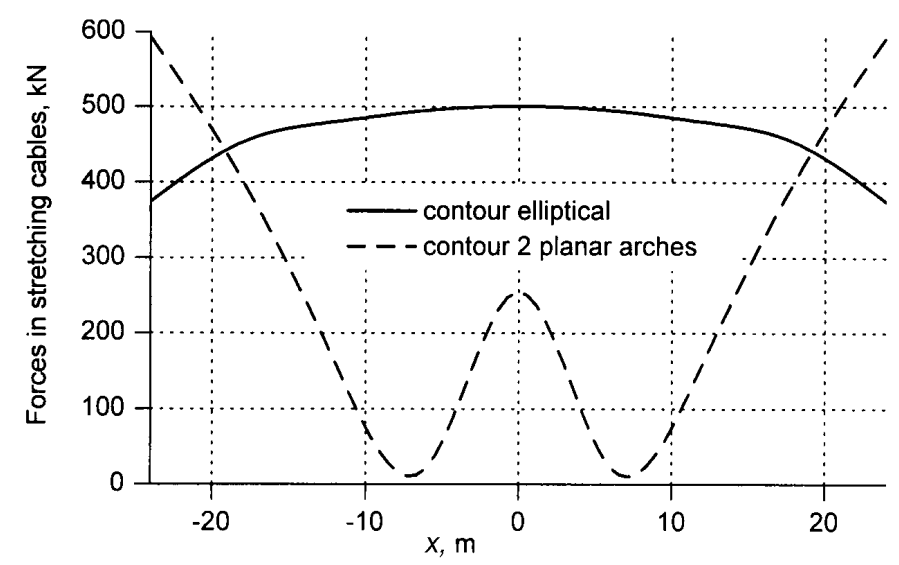

Fig. 10. Deflection of the central carrying cable on $x$ axis with uniform network loading $p=2 \mathrm{kN} / \mathrm{m}^{2}$. 


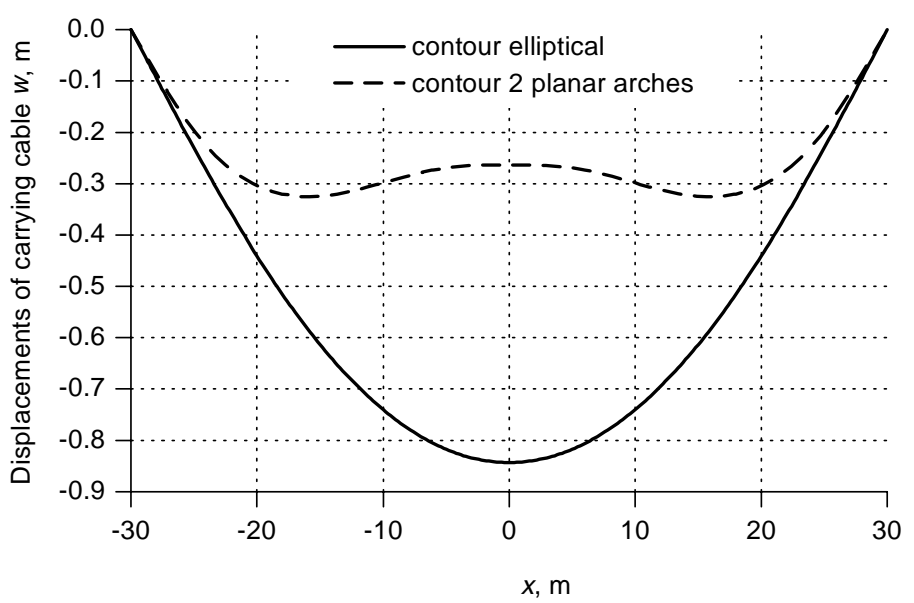

Fig. 11. Forces in stretching cables with uniform network loading $p=2 \mathrm{kN} / \mathrm{m}^{2}$.

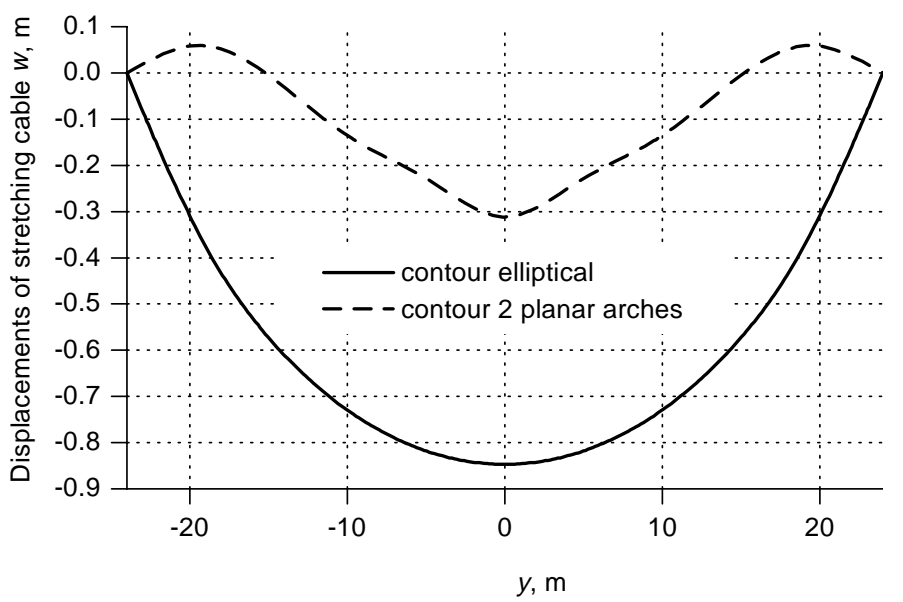

Fig. 12. Forces in carrying cables with uniform network loading $p=2 \mathrm{kN} / \mathrm{m}^{2}$.

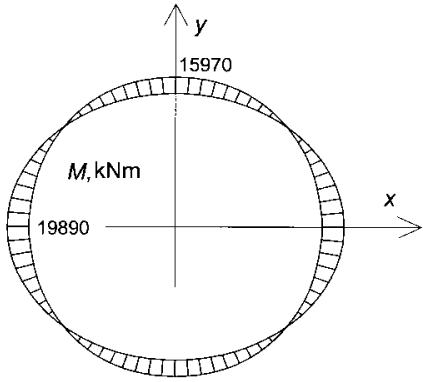

Hypar-network with elliptical contour beam

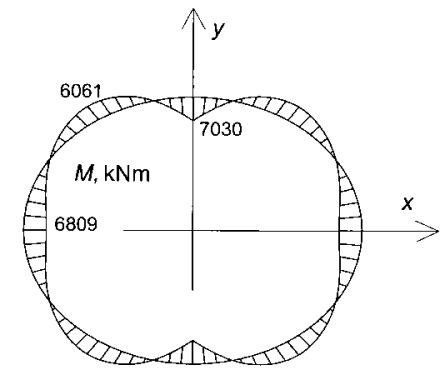

Network with contour of two planar arches

Fig. 13. Bending moment in the contour beam with uniform network loading $p=2 \mathrm{kN} / \mathrm{m}^{2}$. 


\section{CONCLUSIONS}

1. Maximum deflections and bending moments in the hypar-network are larger than in the saddle-shaped network with contour supported by counterforts.

2. Networks, formed inside a counterfort-supported contour beam of two planar arches, have characteristic regions with different curvatures. Relatively flat regions near the arch crowns are especially unfavourable as they tend to loose contact load and are susceptible to the action of fluctuating wind.

3. Networks, formed inside a contour beam of two planar arches, need considerably greater prestressing forces than the hypar-network with elliptical layout to keep stretching cables in tension.

4. Distribution of cable forces is more uniform in hypar-network with an elliptical freely deformable contour beam.

5. The hypar-network with elliptical layout does not need massive counterforts because of effective action of the stretching cables.

6. Efficient solutions for hypar-networks assume careful selection of geometrical factors and structural parameters.

\section{ACKNOWLEDGEMENT}

Support of the Estonian Science Foundation (grant No. 4271) is gratefully acknowledged.

\section{REFERENCES}

1. Kollar, L. and Szabo, J. Structural Design of Cable-suspended Roofs. Ellis Horwood, Chichester, 1984.

2. Buchholdt, H. A. An Introduction to Cable Roof Structures. Thomas Telford, London, 1999.

3. Argyris, J. H. and Scharpf, D. W. Large deflection analysis of prestressed networks. J. Struct. Div. (Proc. ASCE), 1972, 98, 633-653.

4. Godbole, P. N., Krishna, P., and Jain, J. K. Boundary effects in suspended roofs. J. Struct. Eng., 1984, 110, 1099-1113.

5. Majowiecki, M. and Zoulas, F. On the elastic interaction between the rope net and space frame anchorage structures. In Proc. Third International Conference on Space Structures. 1984, Guildford (Nooshin, H., ed.). Elsevier Science, London, 1984, 778-784.

6. Mitsugi, J. Static analysis of cable networks and their supporting structures. Comput. Struct., 1994, 51, 47-56.

7. Laul, H. and Kulbach, V. Analysis of cable network with negative Gaussian curvature. J. Struct. Mech., 1974, 7, 3-18.

8. Kulbach, V. Behaviour of tubular contour of hypar-formed hanging roofs. In Tubular Structures (Mäkeläinen, P. and Niemi, E., eds.). Elsevier Science, London, 1990, 437-442.

9. Kulbach, V. A System of nondimensional parameters for evaluation of different cable systems. In Modern Building Materials, Structures and Techniques (5th International Conference), Vilnius, 1997, 194-199.

10. Kulbach, V. Statical analysis of girder- or cable-stiffened suspended structures. In Proc. Estonian Acad. Sci. Eng., 1995, 1, 2-19. 


\title{
Erineva kontuuriga sadulakujuliste võrk-rippkatuste töö analüiüs
}

\begin{abstract}
Valdek Kulbach, Juhan Idnurm ja Ivar Talvik
Enamiku seni ehitatud võrk-rippkatuste kontuur on moodustatud kahest kaldu asetatud tasapinnalisest kaarest. Siinse uurimuse tulemuste kohaselt on hüparikujulise rippkatuse elliptilisel, rõhtsuunas vabalt deformeeruval kontuuril mitmeid eeliseid võrreldes kahest kaarest kontuuriga. Nendeks on nii trosside kui ka kontuuri sisejõudude ja siirete ühtlasem jaotus ning märkimisväärselt väiksem vajalik trosside eelpingestusjõud. Konstruktsiooni töö uurimiseks on kasutatud nii diskreetset kui ka pidevat arvutusmudelit. Viimase juures on lähtutud dimensioonita parameetrite süsteemist, mis võimaldab arvutustulemusi üldistada. Graafikutel on esitatud hüparikujulise rippkatuse sisejõudude ja siirete sõltuvus konstruktsiooni põhiparameetritest. Oluliselt mõjutab süsteemi tööd kontuuri jäikus ja geomeetria. Esitatud on ka elliptilise ja kahest kaarest kontuuriga võrkkonstruktsiooni siirete ja sisejõudude võrdlusgraafikud.
\end{abstract}

